\title{
Cytological screening to detect subclinical anal human papillomavirus (HPV) infection in homosexual men attending genitourinary medicine clinic
}

\author{
K R HAYE, * H MAITI,* CYNTHIA M STANBRIDGE $\dagger$ \\ From the *Department of Genitourinary Medicine, The Royal Infirmary, and the $†$ Department of Cytology, \\ St Mary's Hospital, Manchester
}

SUMMARY Unselected homosexual men attending a department of genitourinary medicine were screened for human papilloma virus (HPV) infection using anal cytology. Satisfactory smears were obtained from 221 patients, and 73 showed cytological abnormality with warty atypia. Abnormal cytology was detected in $55(31 \%)$ of 178 patients in whom there was no macroscopic evidence of anal or perianal warts, and anal cytology may therefore be valuable to detect patients with subclinical condylomatous lesions and may also serve to identify those who possibly have intraepithelial neoplasia.

During the past decade clinical human papillomavirus (HPV) infection of the genital tract in both sexes has at least doubled. HPV appears to be a highly infective sexually transmissible agent. Nevertheless the true prevalence of infection with HPV is certainly much higher than previously suspected, as subclinical lesions may be detected only by cytology and colposcopy. ${ }^{12}$ HPV infection is strongly associated with the development of neoplasia of the cervix, ${ }^{34}$. the vulva and perianal region, ${ }^{5}$ and on rare occasions of the penis. ${ }^{6}$

In 1971, in a retrospective study of 500 homosexual men, Oriel reported that anal warts were seven times more common than penile warts. ${ }^{7}$ Because of the current rising incidence of this infection in homosexual men this trend may also influence the incidence of anorectal neoplasia, especially in immunocompromised patients. In October 1983 we therefore began a pilot study to assess the importance of anal cytology in detecting subclinical HPV infection in homosexual men attending the department of genitourinary medicine in Manchester.

\section{Patients and methods}

During the two years from October 1983 to September

Address for reprints: Dr K R Haye, Department of Genitourinary Medicine, Royal Infirmary, Oxford Road, Manchester M13 9WL

Accepted for publication 21 May 1988
1985 we used anal cytology to screen 264 unselected homosexual men for HPV infection. All patients had had more than one sexual partner and all had been exposed to anal sex. Patients' consent was obtained for anal cytology, and smears were taken through a proctoscope. Cotton wool swabs moistened in normal saline were used in preference to wooden spatulas. One swab was gently stroked several times against the mucosal wall of the anal canal, and a second was used to take material from the perianal region as the proctoscope was withdrawn. The material on these swabs was immediately spread on clean glass slides and fixed in cytological fixative containing $5 \%$ formaldehyde. All the smears were reviewed by one of us (CMS) without her knowing the clinical findings. Smears were screened, and inflammatory changes, warty atypia, and dyskaryosis was recorded (see below). For this study all smears showing normal squamous cells as well as those with inflammatory changes were considered to be "negative", whereas those with warty atypia or dyskaryosis were designated "abnormal".

Patients with abnormal smears were asked to attend for further examination and we attempted to repeat their cytology tests within two to three months, but compliance was poor and only 40 patients attended for re-examination. Seven of the patients with smears that showed dyskaryosis or pronounced warty atypia underwent colposcopic examination of the anal canal and perianal region (fig 1), and directed biopsy specimens were taken from them under local 


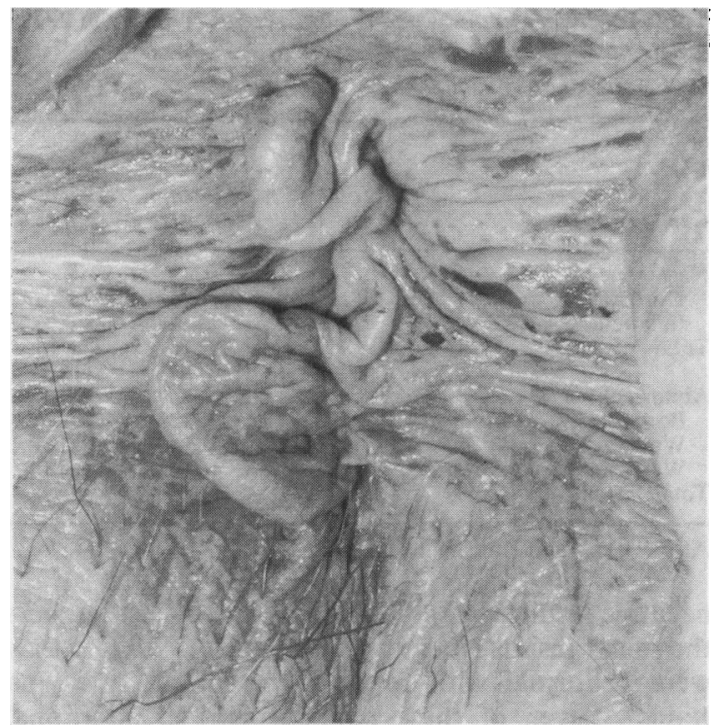

Fig 1 Colposcopic appearance of perianal region showing acetowhite area.

anaesthesia. Anal and perianal smears were taken as controls from 11 men attending a gastroenterology clinic for proctoscopy for conditions unrelated to sexually transmitted diseases. None of these patients had clinically obvious warts.

\section{CLASSIFICATION OF CYTOLOGY RESULTS}

\section{Unsatisfactory}

Smear results were classified as unsatisfactory if the cellular content was poor, the material present consisted of only pus or faecal debris, or cells were distorted because of inadequate fixation.

\section{Normal}

The cytological appearances of normal material from the anal canal and perianal region were more like those usually seen in vulval material than in cervical material. Anucleate squamous cells predominated in smears from the perianal region and were also plentiful in smears from the anal canal, which also contained nucleated mature squamous cells and occasional well preserved rectal columnar cells or degenerate intestinal epithelial cells.

\section{Inflammatory}

Smears containing heavy inflammatory exudate with squamous cells that showed degenerative changes consisting of slight nuclear enlargement, karyorrhexis, karyolysis, or perinuclear halo formation, but no definite warty atypia or dyskaryosis, were described as inflammatory.

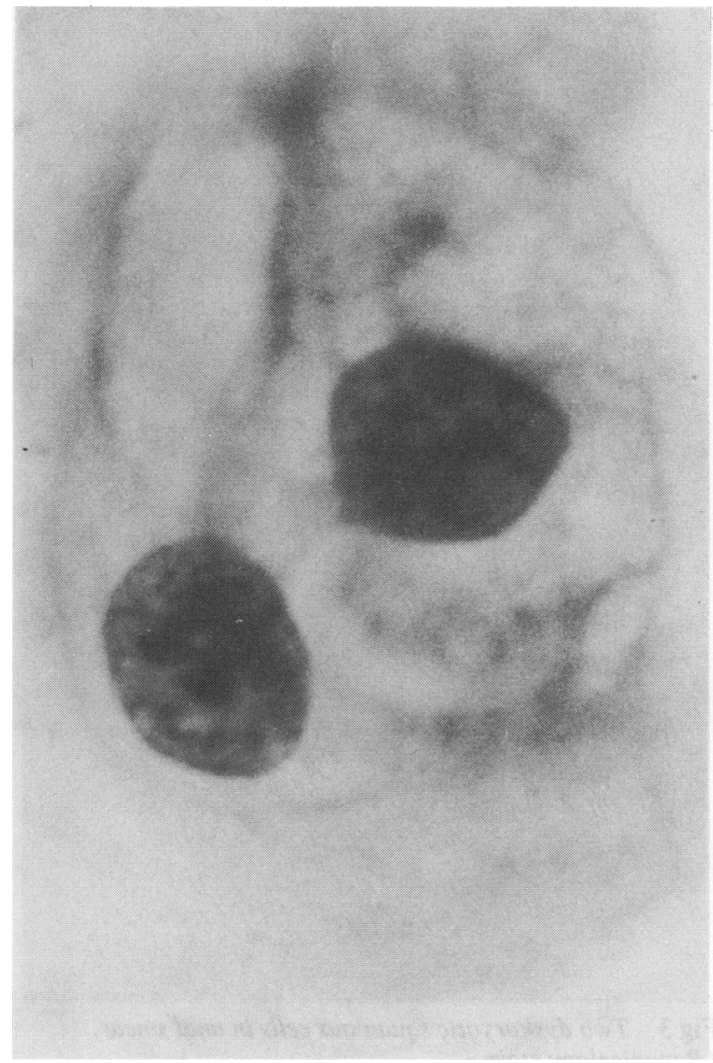

Fig 2 Binucleate squamous cell from anal smear showing koilocytotic atypia. (Papanicolaou stain.)

\section{Borderline}

These smears often showed inflammation with inflammatory cell changes, but cellular atypia (see below) suggesting HPV infection was also seen. Although the atypical cells in these cases were scanty or degenerate, or both, they were nevertheless considered to suggest $\mathrm{HPV}$ infection.

\section{Warty atypical}

Koilocytotic atypia is the cell change that is generally considered to be pathognomonic of HPV infection. ${ }^{1}$ Although it was seen occasionally in anal and perianal smears (fig 2), it was much less common than is found in cervical smears. As with vulval smears from women with condylomatous lesions, the cell changes in anal smears that suggested HPV infection consisted of nuclear enlargement with multinucleation (usually binucleation) and dyskeratosis. Dyskeratotic cells have abnormally keratinised cytoplasm that stains a dense orange-red with Papanicolaou staining, and the nuclei are enlarged, hyperchromatic, and often pyknotic. 


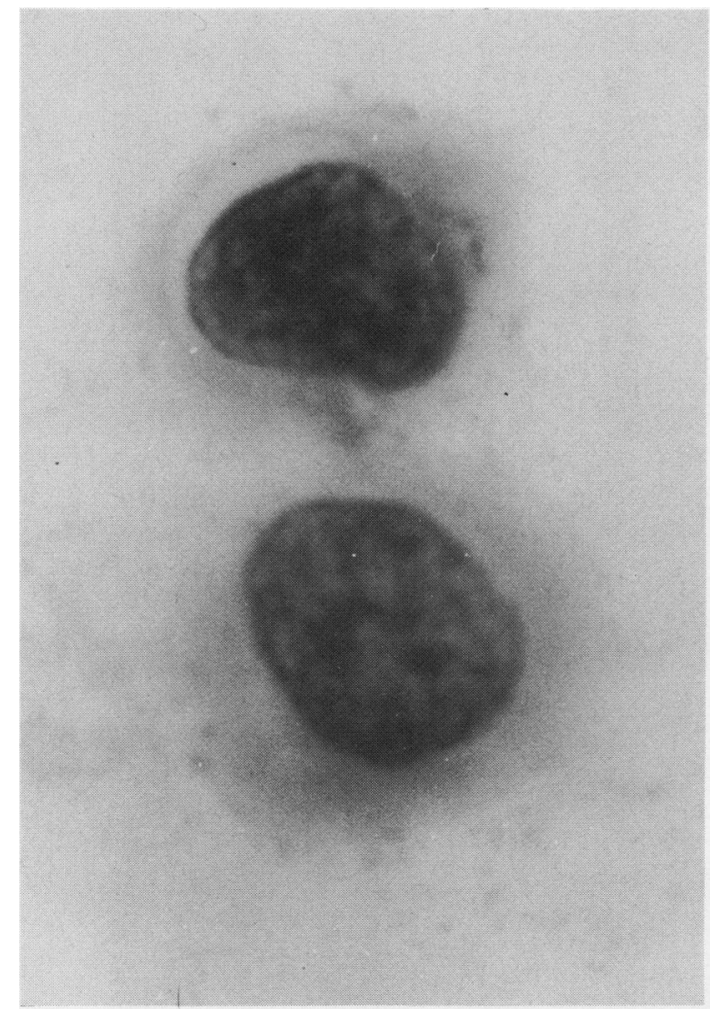

Fig 3 Two dyskaryotic squamous cells in anal smear. (Papanicolaou stain.)

Dyskaryotic

Some smears showing warty atypia also showed quite pronounced nuclear abnormalities, which were comparable with those seen in cervical smears from women with cervical intraepithelial neoplasia (CIN) grades I and II. The possibility of anal intraepithelial neoplasia (AIN) was therefore suggested. The affected cells were mature or moderately mature squamous cells with enlarged, somewhat irregular, and hyperchromatic nuclei (fig 3). Many of these cells also showed multinucleation.

\section{Results}

We took smears from 264 patients, of whom 43 were excluded from the study because their smears were technically unsatisfactory. The mean age of the 221 patients included was 27.

We took repeat smears from 40 men to confirm earlier abnormal cytology results. To avoid overestimation of abnormality, however, the results refer to the number of men screened and not to the number of smears examined.

All the smears from the 11 control patients gave
Table Clinical findings and results of anal cytology in 221 unselected homosexual men (figures are numbers (percentages) of men)

\begin{tabular}{llll}
\hline & & \multicolumn{2}{l}{ Clinical warts: } \\
\cline { 3 - 4 } Cytology results & $\begin{array}{l}\text { Total } \\
(n=221)\end{array}$ & $\begin{array}{l}\text { Absent } \\
(n=178)\end{array}$ & $\begin{array}{c}\text { Present } \\
(n=43)\end{array}$ \\
\hline Negative: & $113(51)$ & $96(54)$ & $17(40)$ \\
$\quad$ Normal & $35(16)$ & $27(15)$ & $8(19)$ \\
$\quad$ Inflammatory & $148(67)$ & $123(69)$ & $25(58)$ \\
Total & & & \\
Abnormal: & $45(20)$ & $37(21)$ & $8(19)$ \\
$\quad$ Borderline warty atypical & $21(10)$ & $13(7)$ & $8(19)$ \\
$\quad$ Warty atypical & $5(3)$ & $2(5)$ \\
Warty and dyskaryotic (AIN) & $7(3)$ & $55(31)$ & $18(42)$ \\
\hline Total & $73(33)$ & 55 &
\end{tabular}

AIN = anal intraepithelial neoplasia.

negative results. In $148(67 \%)$ of the 221 test patients the smear results were negative, and in $73(33 \%)$ they were abnormal with some degree of warty atypia (table). Seven of these patients showed additional dyskaryosis, which suggested the presence of anal

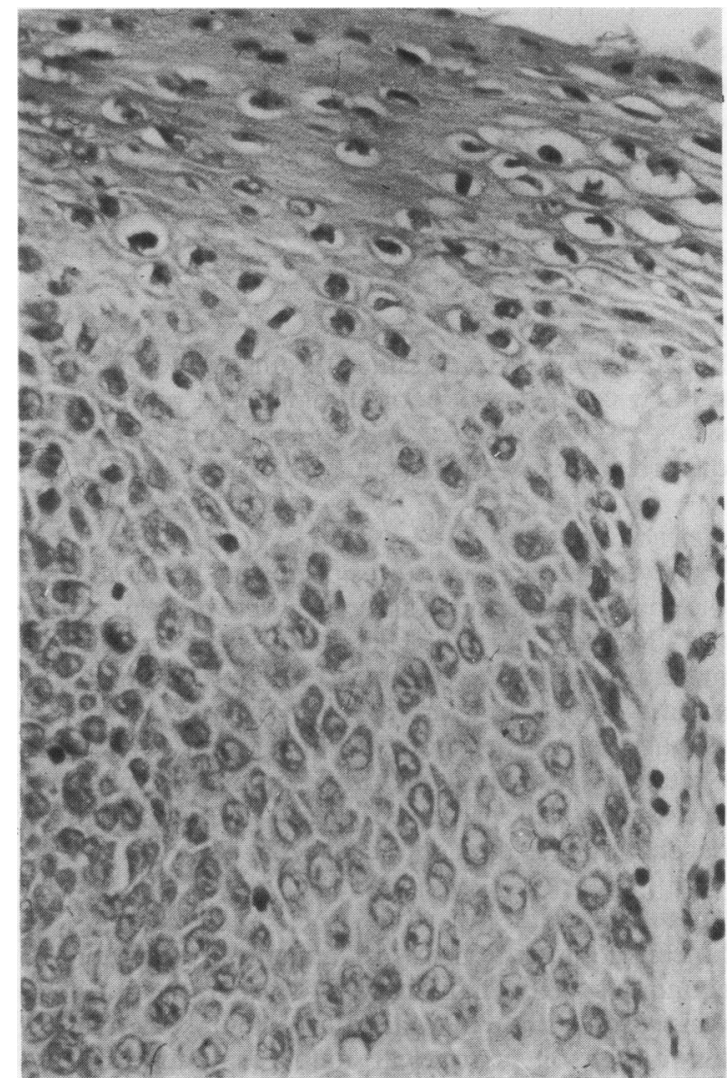

Fig 4 Anal flat condyloma showing surface parakeratosis and koilocytosis. (Haematoxylin and eosin.) 
intraepithelial neoplasia (AIN). We found no visible warts in 178 men at the time of taking the smears, and $123(69 \%)$ of these men had negative smear results, though $55(31 \%)$ had some cytological abnormality that suggested the presence of a condylomatous lesion (HPV infection), five of whom had additional dyskaryosis (table). Eleven of the 55 patients with abnormal cytology results subsequently developed clinically obvious exophytic warts.

Of all 264 patients, $43(16 \%)$ had anal or perianal warts at presentation, 25 of whom had negative smears and 18 had abnormal smears. Seven of the patients with dyskaryotic or severely warty smears underwent colposcopy, the detailed results of which will form the basis of a further report. One of them showed exophytic perianal warts, but the other six had no macroscopically visible lesions before the application of $4 \%$ acetic acid. In all patients the application of acetic acid showed areas of flat white epithelium in the anal canal, the perianal region, or both. Biopsy specimens were taken from this white epithelium, and histological examination confirmed the presence of flat condylomatous lesions (fig 4) in all cases, with additional intraepithelial neoplasia in three patients, which was of grade II severity in one man and grade III severity in the other two.

\section{Discussion}

In a pilot study of 102 homosexual men, many of whom had previously had external anal condylomata, Medley reported that $44 \%$ showed cytological features that suggested residual HPV infection. ${ }^{8}$ That figure compares reasonably with ours of $33 \%$, but a second report from the same centre showed warty atypia in a much higher proportion ( $72 \%)$ of cases. ${ }^{9}$ In these two Australian studies smears were taken using a wooden tongue depressor, and this technique possibly resulted in more cellular samples. Our experience shows, however, that smears taken from the vulva and the anal region with a wooden spatula show more distortion, because of drying before fixation, than smears taken with a moistened cotton swab, and we therefore prefer the latter method.

This study showed that $58 \%(25 / 43)$ of patients with clinically obvious exophytic anal or perianal warts yielded anal smears that failed to show warty atypia and could be considered to be "falsely" negative. Similarly, in their investigation of 61 homosexual men, Frazer et al showed negative results in $30 \%$ of 23 patients with anal warts. ${ }^{9}$ This phenomenon of negative cytology results for patients with obvious warts accords with our observations about genital warts in women (Stanbridge, unpublished observations) and is probably caused by several factors. Histological sections of condylomata acuminata typically show a papillary configuration, with fibrovascular cores covered by thickened squamous epithelium showing hyperkeratosis and parakeratosis. Some koilocytosis with multinucleation and individual cell keratinisation is usual, but the degree of nuclear atypia is variable and may be minimal. Negative smears from patients with such warts may be the result of dense surface hyperkeratosis, in which case only anucleate squamous cells exfoliate. If hyperkeratosis is insignificant, negative smears may also be expected if nuclear atypia is minimal. Only when there is surface parakeratosis with nuclear atypia can dyskeratotic cells be detected in smears. Studies of the fine structure of skin warts ${ }^{10}$ and a benign condyloma ${ }^{11}$ have also shown that there are numerous desmosomal attachments between the constituent squamous cells of these warts, which possibly results in a very stable epithelium and poor cellular exfoliation from the surface.

In contrast, flat condylomatous lesions in the lower genital tracts of women are recognised at colposcopy carried out after finding abnormal cytology results. This study suggests that anal cytology could play a similar part in detecting flat (subclinical) condylomatous lesions of the anal canal in homosexual men. Warty atypia was seen in smears from $31 \%(55 /$ 178) patients who had no visible warts at the time of presentation, but it is interesting to note that in 11 of these patients clinical warts developed subsequently. In 1977 Meisels et al also noted that cervical cytology showed warty atypia before lesions were colposcopically visible.' Cellular exfoliation of cytologically recognisable cells infected with HPV possibly precedes the appearance of clinical or subclinical condylomatous lesions.

Seven of the patients with abnormal cytology results, only one of whom had exophytic perianal warts, were examined colposcopically; flat condylomatous lesions in the anal canal or perianal region were confirmed by biopsy of all seven patients. Three also showed intraepithelial neoplasia, which was of grade II severity in one and grade III severity in the other two. Anal cytology is relatively easy to perform and, although a high proportion of smears are unsatisfactory and false negative cytology results occur despite the presence of exophytic warts, anal cytology may well be of value in detecting patients with flat (subclinical) condylomatous lesions, particularly in those without exophytic warts. Anal cytology also serves to identify patients who possibly have associated intraepithelial neoplasia. The natural history of HPV infection and intraepithelial neoplasia in the anal region is not known but, as in the lower genital tract of women, HPV infection is probably related to the development of anal intraepithelial neoplasia and invasive carcinoma. 
Squamous cell carcinoma of the anus is uncommon, but it has been reported in association with anal warts. ${ }^{12-14}$ Anal epithelial atypia and intraepithelial neoplasia in relation to condylomatous lesions are also being reported increasingly in homosexual men. ${ }^{915-17}$ We therefore suggest that anal cytology should form part of the investigation of homosexual men attending departments of genitourinary medicine and that regular surveillance by cytology and colposcopy might be considered for men showing evidence of warty atypia and dyskaryosis.

We thank Dr T Warnes of the department of gastroenterology of Manchester Royal Infirmary, for allowing us to carry out a control study of his patients, and our colleagues and nursing and secretarial staff for their co-operation.

\section{References}

1 Meisels A, Fortin R, Roy M. Condylomatous lesions of the cervix. II. Cytologic, colposcopic and histopathologic study. Acta Cytol (Baltimore) 1977;21:379-90.

2 Reid R, Laverty C, Coppleson M, Isarangkul W, Hills E. Noncondylomatous cervical wart virus infection. Obstet Gynaecol 1980;55:476-83.

3 Campion MJ, Singer A, Clarkson PK, McCance DJ. Increased risk of cervical neoplasia in consorts of men with penile condylomata acuminata. Lancet 1985;i:943-6.

4 Walker PG, Colley NV, Grubb C, Tejerina A, Oriel JD. Abnormalities of the uterine cervix in women with vulval warts: a preliminary communication. British Journal of Venereal Diseases 1983;59:120-3.

5 Stanbridge CM, Butler EB. Human papillomavirus infection of the lower female genital tract: association with multicentric neoplasia. Int J Gynecol Pathol 1983;2:264-74.

6 Zachow KR, Ostrow RS, Bender M, et al. Detection of human papillomavirus DNA in anogenital neoplasias. Nature 1982; 300:771-3.

7 Oriel JD. Anal warts and anal coitus. British Journal of Venereal Diseases 1971;47:373-6.

8 Medley G. Anal smear test to diagnose occult anorectal infection with human papillomavirus in men. British Journal of Venereal Diseases 1984;60:205.

9 Frazer IH, Medley G, Crapper RM, Brown TC, Mackay IR. Association between anorectal dysplasia, human papilloma virus and human immunodeficiency virus infection in homosexual men. Lancet 1986;ii:657-60.

10 Charles A. Electron microscope observations on the human wart. Dermatologica 1960;121:193-203.

11 Kovi J, Tillman RL, Lee SM. Malignant transformation of condyloma acuminatum. Am J Clin Pathol 1974;61:702-10.

12 Sturm JT, Christenson CE, Uecker JH, Perry JF. Squamous-cell carcinoma of the anus arising in a giant condyloma acuminatum: report of a case. Dis Colon Rectum 1975;18:147-51.

13 Li FP, Osborn D, Cronin CM. Anorectal squamous carcinoma in two homosexual men. Lancet 1982;ii:391.

14 Schinella RA, Selvaggi SM, Morgan DM, et al. Papillomavirus in anorectal condyloma acuminatum with malignant transformation detected by molecular hybridization and immunoperoxidase technique, abstracted. Lab Invest 1985;52:59A.

15 Oriel JD, Whimster IW. Carcinoma in situ associated with viruscontaining anal warts. Br J Dermatol 1971;84:71-3.

16 Croxson T, Chabon AB, Rorat E, Barash IM. Intraepithelial carcinoma of the anus in homosexual men. Dis Colon Rectum 1984;27:325-30.

17 Nash G, Warren A, Nash S. Atypical lesions of the anal mucosa in homosexual men. JAMA 1986;256:873-6. 